\title{
LABOR PRODUCTIVITY GROWTH IN THE EU - GAP AMONG THE MEMBER STATES
}

\author{
Oana Ancuţa Stângaciu \\ Vasile Alecsandri University of Bacău \\ anca_stangaciu@yahoo.com
}

\begin{abstract}
In our endeavor to analyze the labor productivity gap among the member states for the period 2000-2015, we started by assessing, on territorial profile, the indicators pertaining to descriptive statistics and the results of the hierarchical cluster analysis. In order to highlight the convergence of labor productivity growth in the EU28, two regression equations have been drawn up, in which the independent variable was labor productivity in 2000, and the dependent variable was the dynamics of the indicator registered in 2015 compared to 2000, respectively its value at the end of the period subjected to the analysis.
\end{abstract}

\section{Keywords}

labor productivity; dendrogram; convergence

\section{JEL Classification}

C10; E24

\section{Introduction}

On the level of the EU28, there was already a gap on territorial profile in the values registered for labor productivity in the economies of the member states. However, the integration of the Central and Eastern countries within the European space led to a decrease in the disparities between the West and the East.

\section{Short methodological presentation}

According to EUROSTAT, labor productivity measures the amount of goods and services produced by each member of the labor force or the output per input of labor. This index can be measured in a variety of ways. For structural indicators, it may be measured by gross domestic product (GDP), expressed in terms of the purchasing power standard (PPS), either relative to the number of employed people or to the number of hours worked. Within national accounts and structural business statistics, labor productivity is often defined as the value added per employed person.

In this analysis, that measures the gap among the member states, the labor productivity per person by country, calculated as the ratio between the GDP expressed in purchasing power standards (PPS) and the aggregate number of employees or self-employed, is used as a percentage of EU28 total-based on million PPS- current prices.

\section{The evolution of the labor productivity gap among the member states}

During the period 2000-2015, the disparities between the EU member states concerning labor productivity, calculated per country as percentage of the EU total, are significant. Thus, during the last 15 years, the amplitude series for labor productivity by country decreased - see Figure 1 and Table 1. While in 2000 the difference between the highest 
value registered (179.4\% in Luxembourg) and the lowest value (23.9\% in Romania) was of 155.5 percentage points, in 2015 this difference (maximum:185.9\% in Ireland, minimum: $44.2 \%$ in Bulgaria) was of only 141.7 percentage points, that is 13.8 percentage points lower than in 2000.

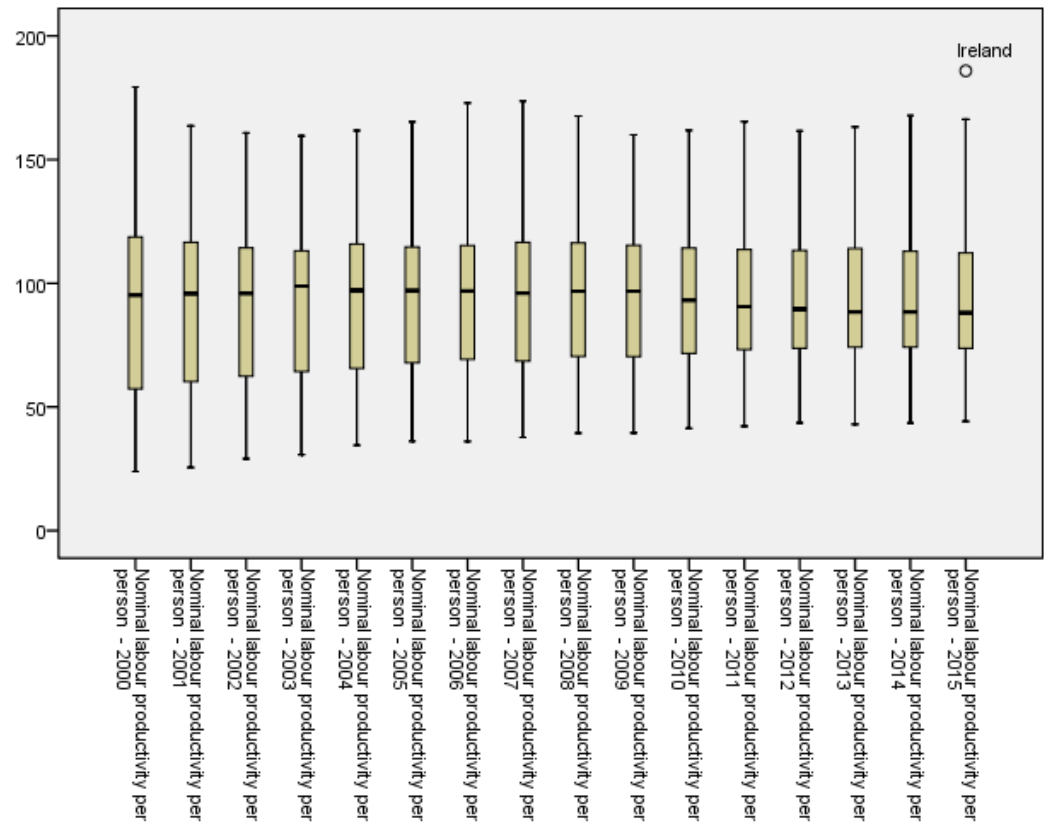

Figure 1 Boxplot of Nominal labor productivity per person (Percentage of EU28 total-based on million PPS-, current prices) for the period 2000-2015

Source: Personal processing of the EUROSTAT available data

The decrease of the gap among the members states is also emphasized - see Table 1 by the evolution of the standard deviation for the series labor productivity by country during the period 2000-2015. Thus, it decreased from 37.960 in 2000 to 27.266 in 2014, and to 30.774 in 2015 respectively. The evolution of the coefficient of the asymmetry Skewness, as well as the boxplot for the series distribution - see Figure 1 and Table 1 - underline the existence of a certain clustering of the countries towards the small values of the series (Skewness has positive values for the whole period subjected to the analysis, except for 2001, 2002 and 2003). The same phenomenon can be noticed in the Histograms drawn up in Figure 2, the distribution of the countries according to the labor productivity quantifying to 15 the number of the member states with a labor productivity below the average of the EU28 (below 100\%) and to only 13 the number of the countries with a labor productivity value over $100 \%$ (except for 2003 , when there were 14 countries with a value over $100 \%$ ), countries with a high level of development, situated in the north and in the west of Europe, which are part of the old Europe (EU15), except for Greece and Portugal. 
Table 1 Descriptive statistics for Nominal labour productivity per person (Percentage of EU28 total-based on million PPS-, current prices) for the period 2000-2015

\begin{tabular}{l|rrrrrrrr}
\multicolumn{7}{c}{ Case Summaries for Nominal labour productivity per person } \\
\hline Year & N & Mean & $\begin{array}{c}\text { Std. } \\
\text { Deviation }\end{array}$ & Skewness & Kurtosis & Variance & Minimum & Maximum \\
\hline 2000 & 28 & 90,075 & 37,960 & 0,092 & $-0,461$ & 1440,974 & 23,9 & 179,4 \\
2001 & 28 & 89,518 & 35,331 & $-0,069$ & $-0,784$ & 1248,248 & 25,5 & 163,6 \\
2002 & 28 & 89,825 & 34,252 & $-0,036$ & $-0,779$ & 1173,169 & 29,1 & 160,8 \\
2003 & 28 & 90,568 & 33,128 & $-0,044$ & $-0,696$ & 1097,451 & 30,7 & 159,6 \\
2004 & 28 & 91,446 & 32,580 & 0,006 & $-0,627$ & 1061,425 & 34,5 & 161,7 \\
2005 & 28 & 92,300 & 31,785 & 0,085 & $-0,378$ & 1010,295 & 36,2 & 165,3 \\
2006 & 28 & 93,054 & 31,868 & 0,239 & 0,024 & 1015,591 & 36,1 & 172,9 \\
2007 & 28 & 93,861 & 31,004 & 0,310 & 0,200 & 961,250 & 37,7 & 173,7 \\
2008 & 28 & 94,057 & 28,931 & 0,237 & 0,078 & 837,012 & 39,4 & 167,6 \\
2009 & 28 & 93,875 & 28,368 & 0,108 & $-0,307$ & 804,743 & 39,5 & 160,0 \\
2010 & 28 & 94,382 & 28,009 & 0,278 & $-0,081$ & 784,530 & 41,3 & 161,8 \\
2011 & 28 & 94,525 & 27,845 & 0,453 & 0,274 & 775,338 & 42,2 & 165,4 \\
2012 & 28 & 94,689 & 27,027 & 0,474 & 0,169 & 730,464 & 43,6 & 161,6 \\
2013 & 28 & 94,682 & 26,767 & 0,480 & 0,339 & 716,460 & 43,0 & 163,2 \\
2014 & 28 & 94,875 & 27,266 & 0,628 & 0,693 & 743,409 & 43,5 & 167,8 \\
2015 & 28 & 95,839 & 30,774 & 1,159 & 2,020 & 947,016 & 44,2 & 185,9 \\
& Source: Personal processing of the EUROSTAT available data &
\end{tabular}

2000

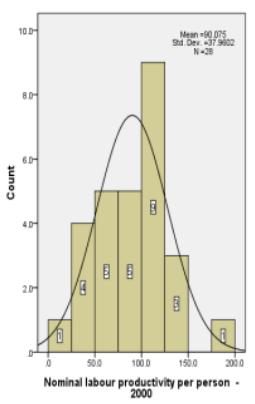

2004

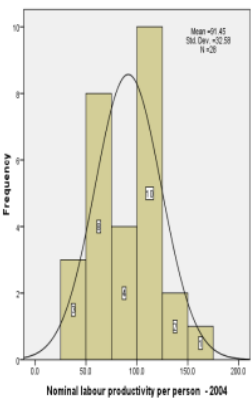

2008

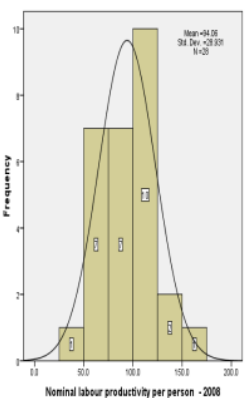

2001

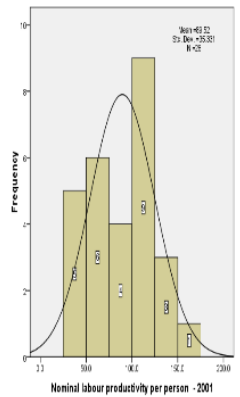

2005

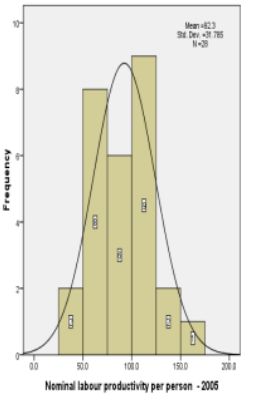

2009

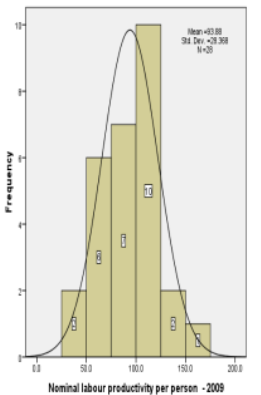

2002

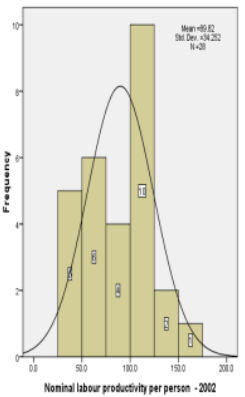

2006

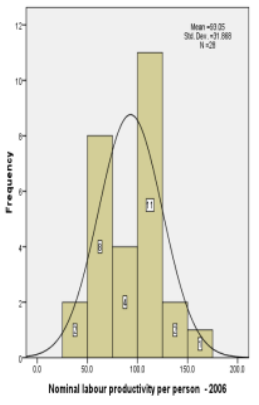

2010

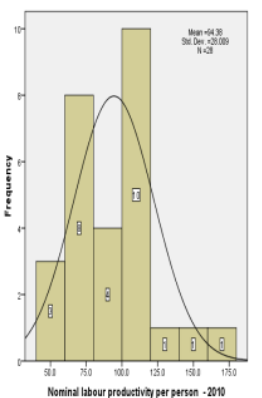

2003

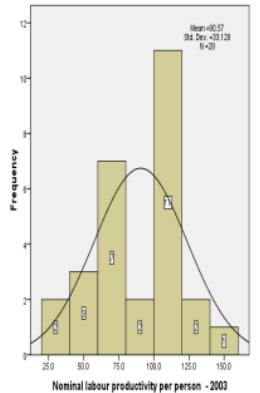

2007

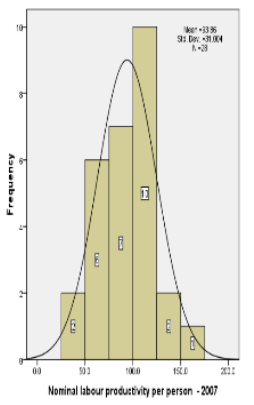

2011

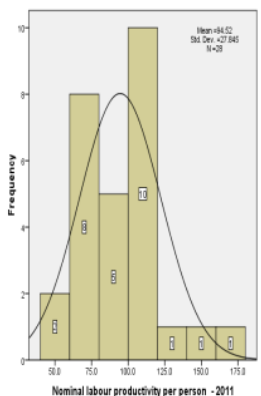


2012

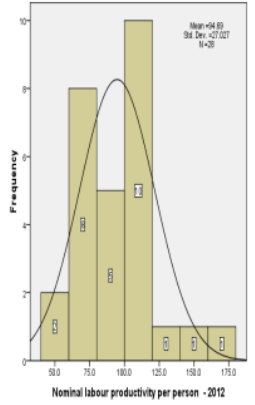

2013

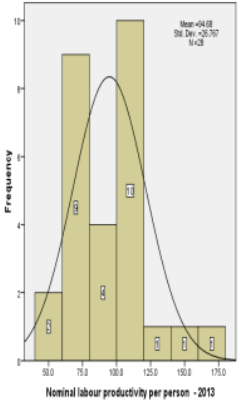

2014

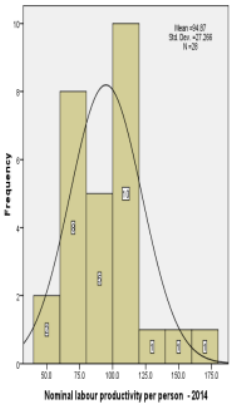

2015

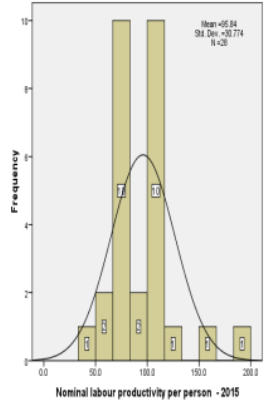

Figure 2 Histogram of Nominal labor productivity per person (Percentage of EU28 total-based on million PPS-, current prices) for the period 2000-2015 Source: Personal processing of the EUROSTAT available data

From the hierarchical cluster analysis (the dendrograms in Figure 3) it can be noticed that both in 2000 and in 2015 the diagram has 2 branches (A and B), and branch B has a single leaf (Luxemburg) in 2000 respectively two leaves (Ireland and Luxemburg) in 2015. It can be noticed that branch A is separated into two branches ( $C$ and $D)$, of which branch $\mathrm{C}$ (for 2015) shows the similarities of labor productivity among the countries in EU15 and branch D the similarities of the value of labor productivity among the countries that entered the EU later. Also, the decrease in the height of the branch point, in 2015 compared to 2000, means a decrease of the gap between the countries which are part of the old and the new EU. As to the dynamics of this indicator during the period of time 2000-2015, the dendrogram in Figure 3 shows the existence of a group of countries (branch B) with high dynamics of the labor productivity and low values of the indicator in 2000. It should also be noticed that on branch B, Romania is the only leaf on branch $\mathrm{F}$, that branch $\mathrm{E}$ has 5 leaves and that there are great differences among the EU member state in the dynamics of labor productivity (great oscillations in the height of the branch).

2000

Dendrogram using Average Linkage (Between Groups)

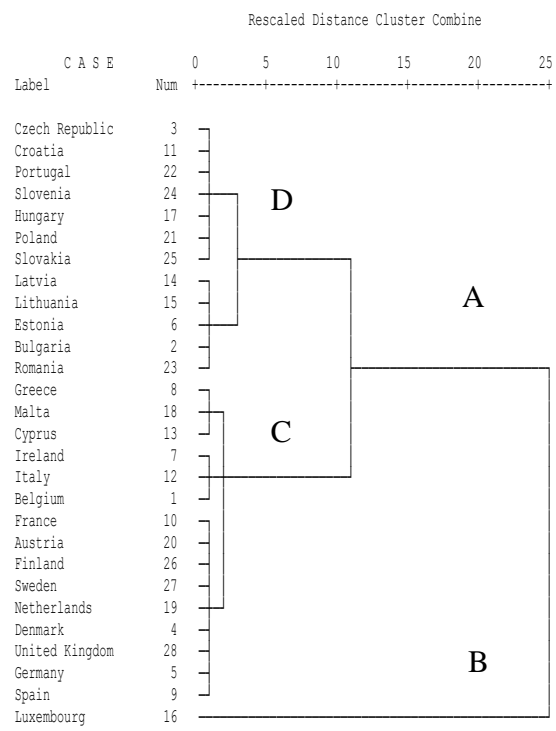

2015

Dendrogram using Average Linkage (Between Groups)

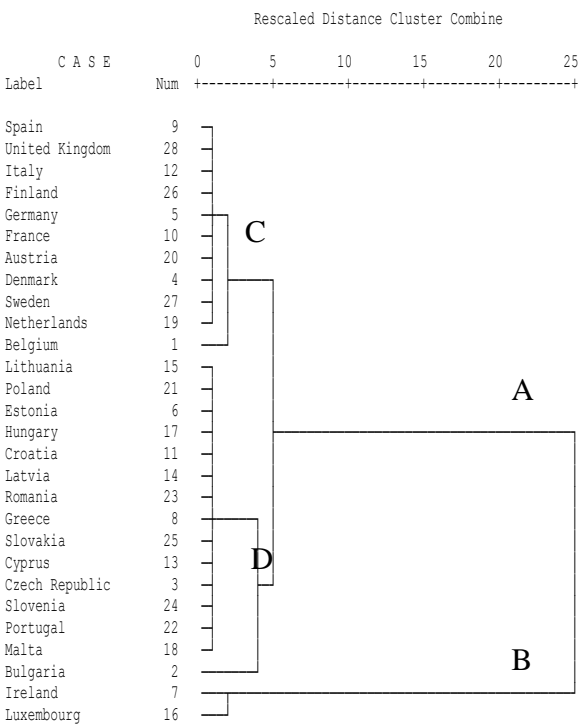




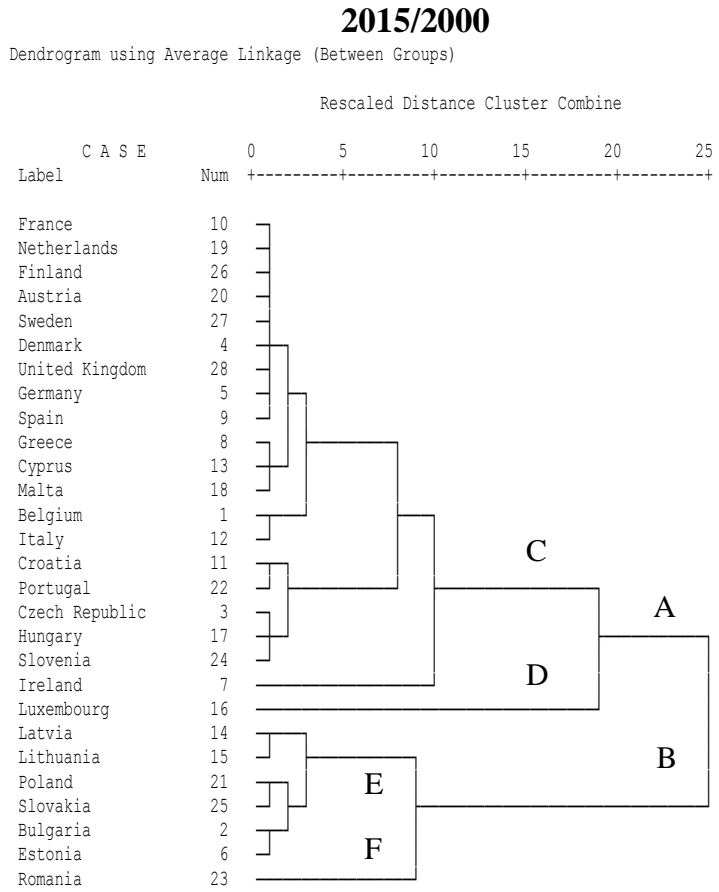

\section{Figure 3 Dendrogram of Nominal labor productivity per person (Percentage of EU28 total-based on million PPS-, current prices) for the years 2000, 2015 and the dynamics of 2015 compared to 2000 \\ Source: Personal processing of the EUROSTAT available data}

\section{The convergence of labor productivity in EU28}

The existence of a convergence process of labor productivity on the level of the EU28 can be emphasized through the econometric connection between the Nominal labor productivity per person by country (Percentage of EU28 total -based on million PPS-, current prices) for 2000 and its dynamics in 2015 compared to 2000. Such an analysis implies drawing up a regression equation, respectively a correlogram, in which the independent variable is the natural logarithm of the Nominal labor productivity per person by country (Percentage of EU28 total -based on million PPS-, current prices) for 2000, and the dependent variable is the dynamics of this indicator in 2015 compared to $2000(2000=100 \%)$.

The regression equation is as follows:

Where:

$$
L W_{2015 / 2000}=\alpha+\beta L N\left(L W_{2000}\right)+\varepsilon
$$

$L W_{2000}=$ Nominal labor productivity per person by country (Percentage of EU28 total -based on million PPS-, current prices) for 2000

$L W_{2015 / 2000}=$ dynamics of the Nominal labor productivity per person by country (Percentage of EU28 total -based on million PPS-, current prices) in 2015 compared to 2000

$\alpha$ and $\beta=$ the parameters of the linear regression equation

$\varepsilon=$ residual error 


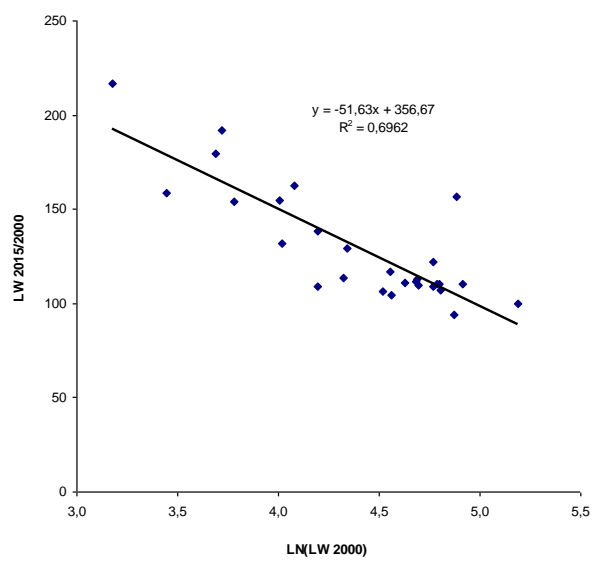

Linear
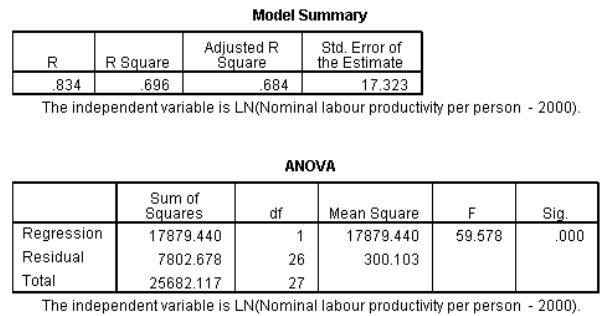

Coefficients

\begin{tabular}{|l|r|r|r|r|r|}
\hline & \multicolumn{2}{|c|}{ Unstandardized Coefficients } & $\begin{array}{c}\text { Standardized } \\
\text { Coefficients }\end{array}$ & & \\
\cline { 2 - 4 } & \multicolumn{1}{|c|}{$\mathrm{B}$} & \multicolumn{1}{|c|}{ Std. Error } & \multicolumn{1}{c|}{ Beta } & \multicolumn{1}{c|}{ Siq. } \\
\hline $\begin{array}{l}\text { LN(Nominal labour } \\
\text { productivity per person - }\end{array}$ & -51.632 & 6.689 & -.834 & -7.719 & .000 \\
$\begin{array}{l}\text { 2000) } \\
\text { (Constant) }\end{array}$ & 356.678 & 29.584 & & 12.056 & .000 \\
\hline
\end{tabular}

Figure 4 Scatterplot of Nominal labor productivity per person (Percentage of EU28 total -based on million PPS-, current prices) for the year 2000 and the dynamics of 2015 compared to 2000; The test report of the regression equation in SPSS

Source: Personal processing of the EUROSTAT available data

As it can be seen in Figure 4, there is a very strong dependence between the two indicators, the nominal labor productivity determining its dynamics in proportion of $69.6 \%$. In other words, the lower the labor productivity of a country was in 2000 , the greater its dynamics during the period of time subjected to the analysis. On the other hand, since the $\beta$ coefficient of the regression equation is lower than 0 , we can state that on the level of the EU28 member states there is a convergence process of labor productivity.

The convergence of labor productivity on the level of the EU28 can also be assessed from the point of view of the structural stability in time of the EU28 member states. This approach, based on the contributions of Cantwell (1989) and Pavitt (1989), implies drawing up a regression equation where the independent variable is the Nominal labor productivity per person by country (Percentage of EU28 total -based on million PPS-, current prices) registered at the beginning of the period of time subjected to the analysis (the year 2000), and the dependent variable is the value of this indicator at the end of the period (the year 2015).

The regression equation is as follows:

$$
L W_{2015}=\alpha+\beta L W_{2000}+\varepsilon
$$


Where: $L W_{2015}$ and $L W_{2000}=$ Nominal labor productivity per person by country (Percentage of EU28 total -based on million PPS-, current prices) for the year 2015 and 2000 respectively

$\alpha$ and $\beta=$ parameters of the linear regression equation

$\varepsilon=$ residual error

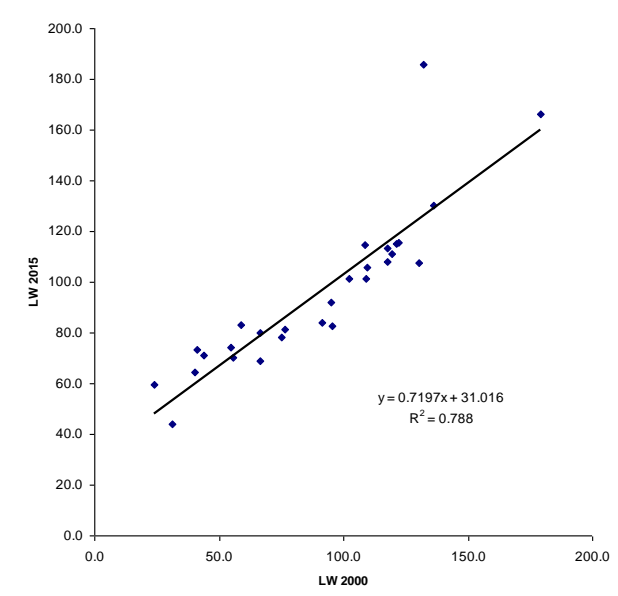

Linear
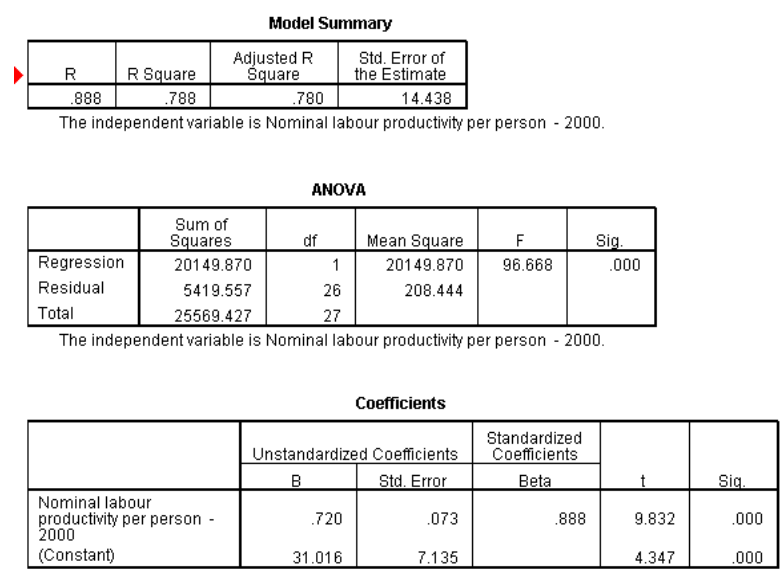

Figure 5 Scatterplot of Nominal labor productivity per person (Percentage of EU28 total-based on million PPS-, current prices) for the years 2000 and 2015; The test report of the regression equation in SPSS

Source: Personal processing of the EUROSTAT available data

On the level of EU28, the relative position of the member states stayed the same on average during the period of time $2000-2015$, since the regression parameter $\beta$ is between 0 and $1(\beta=0.72)$-see figure 5-, with only slight repositioning of the countries, meaning that there may have been greater increases in the labor productivity in the case of the countries with low values and respectively greater decreases in the case of the countries where there were high values of the indicator. Also, the value close to 1 of the $\beta$ parameter for the regression equation and the great value of the correlation coefficient $(R=0.89)$, indicate the fact that there were no significant changes in the distribution of the labor productivity on territorial profile. 


\section{Conclusions}

During the last 15 years, the gap among the member states decreased, thus the series amplitude by country being reduced, as well as the value of the standard deviation indicator. We could also notice that there is a certain clustering of the countries towards the low values of the series, with 15 member states having a labor productivity below the EU28 average (below 100\%), and 13 countries having a labor productivity over $100 \%$.

These results are also validated through the hierarchical cluster analysis. Thus, the dendrogram has only 2 branches, one branch has a single leaf (Luxemburg) in 2000 and two leaves respectively (Ireland and Luxemburg) in 2015, while the other branch A is split into two branches, one of which being made up of a single country of the EU15. As to the dynamics during the period 2015-2000, the dendrogram shows the existence of a branch with countries that have a high labor productivity dynamics and low values of the indicator in 2000, while Romania is a single leaf on another branch.

The information offered by the descriptive statistics concerning the existence of a convergence process on the level of the EU28 is also confirmed by the econometric analysis. Thus, on the level of the EU28 member states there was, on one hand, a convergence of the labor productivity during the period of time 2000-2015, and the level of the labor productivity in 2000 determined its dynamics during the period subjected to the analysis in proportion of $69.6 \%$, and on the other hand there were no significant changes in the distribution on territorial profile of the labor productivity, but only slight repositioning of the countries in the general hierarchy.

\section{References}

Barro, R., Sala-i-Martin, X. (1992), Convergence, Journal of Political Economy, $100(2)$.

Cantwell, J. (1989), Technological Innovation and Multinational Corporations, Oxford, Basil Blackwell.

Hallet, M. (2000), Regional specialization and concentration in EU, Economic papers - European Commision, No. 141.

Quah, D. (1993), Empirical cross-section dynamics in economic growth, European Economic Review, No. 37.

Quah, D. (1996), Empirics for economic growth and convergence, European Economic Review, No. 40.

Pavitt, K. (1989), International patterns of technological accumulation, Strategies in global competition, London, Croom Helm Publisher.

Persson, J. (1994), Convergence in per capita income and migration across the Swedish counties 1906-1990, Institute for International Economic Stockholm University - Series Seminar Papers, No. 601.

Redding, S. (2002), Specialization dynamics, Journal of International Economics, No. 58(1).

Stângaciu, O.A. (2012), The Mobility Of The Processes Of Regional Intra-Industry Specialization In Romania, CES Working Papers, Centre for European Studies, Alexandru Ioan Cuza University, Vol. 4(2).

EUROSTAT, data set, available at URL (http://ec.europa.eu/eurostat). 